Độ nhạy và độ đặc hiệu của ROMA trong UTBT chung là $81.81 \%$ và $68.75 \%$; trong nhóm đang có kinh là $78.94 \%$ và $65.18 \%$; và nhóm mãn kinh thì độ nhậy, độ đặc hiệu này cao hơn rất nhiêu lần lượt là $85.71 \%$ và $100 \%$, riêng trong nhóm UTBMBT, ROMA có độ nhạy cao nhất $92 \%$. Kết qủa của chúng tôi tương tự kết quả tác giả trong nước: nghiên cứu của Võ Thanh Nhân (2010) độ nhay của ROMA là 88,2\% và độ đặc hiệu là $64,3 \%$, nhưng khác với tác giả nước ngoài: Anton và cộng sự (2012) nghiên cứu trên 128 bệnh nhân cho thây độ nhay của ROMA là $74,1 \%$ và độ đặc hiệu là $75,8 \%$, nghiên cứu của Su Wei và cộng sự trên 158 trường hợp có độ nhạy 93,75\% và độ đặc hiệu 92,55\%. Karlsen và cộng sự khuyến nghi sử dụng ROMA đặc biệt là ở phụ nữ mãn kinh để dự đoán UTBT chính xác hơn.

Từ những kết quả của nghiên cứu này, chúng tôi nhận thấy: các xét nghiệm CA125, HE4 và ROMA test đều có giá trị tốt để chẩn đoán UTBMBT và cả UTBT nói chung. Nhưng HE4 riêng lẻ hoặc kết hợp HE4 và CA125 có giá trị tốt hơn so với CA125 đởn thuần.

\section{KẾT LUÂN}

Các chất chỉ điểm khối u CA125, HE4 và ROMA test đều có giá trị tốt trong chẩn đoán UTBT nói chung và UTBMBT nói riêng. ROMA cho độ nhạy cao nhất là $92 \%$ và HE4 cho độ đặc hiệu cao nhất $96.6 \%$ trong UTBMBT. Nên kết hợp CA125 và HE4 trong dự đoán UTBMBT.

\section{TÀI LIÊU THAM KHẢO}

1. Pearce C.L., Stram D.O., Ness R.B. et al. (2015). Population Distribution of Lifetime Risk of Ovarian Cancer in the United States. Cancer Epidemiol Biomarkers \&amp;amp; Prev, 24(4), $671 \mathrm{LP}-676$.

2. Ferlay J., Soerjomataram I., Dikshit R. et al. (2015). Cancer incidence and mortality worldwide: sources, methods and major patterns in GLOBOCAN 2012. Int J cancer, 136(5), E359-86.

3. Li K., Hüsing A., Fortner R.T. et al. (2015). An epidemiologic risk prediction model for ovarian cancer in Europe: The EPIC study. $\mathrm{Br}$ J Cancer, 112(7), 1257-1265

4. LaVigne K., Dao F., Abu-Rustum N. et al. (2017), HE4 is a biomarker for newly diagnosed and recurrent high - grade serous ovarian cancer with normal CA 125 values.

5. Moore R.G., McMeekin D.S., Brown A.K. et al. (2009). A novel multiple marker bioassay utilizing HE4 and CA125 for the prediction of ovarian cancer in patients with a pelvic mass. Gynecol Oncol, 112(1), 40-6.

6. Aslam N., Banerjee S., Carr J. V et al. (2000). Prospective evaluation of logistic regression models for the diagnosis of ovarian cancer. Obstet Gynecol, 96(1), 75-80.

7. Piek J.M.J., van Diest P.J., Verheijen R.H.M. (2008). Ovarian carcinogenesis: an alternative hypothesis. Adv Exp Med Biol, 622, 79-87.

8. Dikmen Z.G., Colak A., Dogan P. et al. (2015). Diagnostic performances of CA125, HE4, and ROMA index in ovarian cancer. Eur J Gynaecol Oncol, 36(4), 457-462.

9. Huy N.V.Q., Van Khoa V., Tam L.M. et al. (2018). Standard and optimal cut-off values of serum ca-125, HE4 and ROMA in preoperative prediction of ovarian cancer in Vietnam. Gynecol Oncol reports, 25, 110-114.

\title{
NGUYÊN NHÂN, XỬ TRÍ VÀ KẾT QUẢ SỚM ĐIỀU TRI THỦNG THỰC QUẢN
}

\section{TÓM TẮT}

Đặt vấn đề: Thủng thực quản là một bệnh lý hiếm gặp nhưng tỉ lệ biến chứng và tử vong cao. Tổn thương có nhiều vị trí và mức độ lan rộng khác nhau khiến việc chẩn đoán ban đâuu thường gặp nhiều khó khăn. Lựa chọn phương pháp điều trị tốt nhất cho bệnh nhân khác nhau tùy vào đặc điểm tổn thương.

*Đại học Quốc Gia TP. Hồ Chí Minh

** Đai hoc Y Dước TP. Hồ Chí Minh

Chịu trách nhiệm chính: Lý Minh Tùng

Email: Imtung@medvnu.edu.vn

Ngày nhận bài: 18.10.2021

Ngày phản biên khoa hoc: 20.12.2021

Ngày duyệt bài: 28.12.2021

\section{Dương Bá Lập**, Lý Minh Tùng*, Trần Văn Minh Tuấn*, Trần Hữu Duy*}

Nghiên cứu này nhằm mô tả nguyên nhân và đánh giá hiêu quả của các phương pháp điều tri thủng thực quản từ 06.2014 đến 06.2019 tại bệnh viện Bình Dân. Muc tiêu: Mô tả nguyên nhân, đắc điểm lâm sàng của tổn thương, hình ảnh học và đánh giá kết quả điều trị các trường hợp thủng thực quản. Đối tượng và phướng pháp nghiên cứu: Mô tả hàng loạt ca được chẩn đoán và điêu trị thủng thực quản tại bệnh viện Bình Dân trong khoảng thời gian 5 năm từ 06.2014 đến 06.2019. Kết quả: Có 36 bệnh nhân, gồm 17 ca thủng thực quản ở cổ (47\%), 15 ca ở ngực (42\%) và 4 ca ở bụng $(11 \%)$. Nguyên nhân chính gầy thủng thực quản là do dị vật $(41,7 \%)$. CT giúp phát hiên tổn thương $94 \%$. Có 8 ca điêuu trị bảo tồn, tỉ lệ thành công là $75 \%$. Khâu thì đâu có tỉ lệ thành công là $87,5 \%$. Tỉ lệ tử vong chung là $8,3 \%$. Kết luận: Thủng 
thực quản cân chẩn đoán sớm để giảm tỉ lệ tử vong. CT-scan là phương tiện hữu ích, cung cấp nhiều thông tin giúp chẩn đoán. Điều trị bảo tồn có thể áp dụng trong những trường hợp chọn lọc. Khâu thì đâuu là một lựa chọn tốt cho thủng thực quản, có tỉ lệ thành công cao. bảo tồn

Tư khóa: thủng thực quản, khâu thì đâu, điều trị

\section{SUMMARY}

ETIOLOGY, MANAGEMENT AND SHORTTERM OUTCOME OF ESOPHAGEAL PERFORATION

Introduction: Esophageal perforations are associated with a high rate of morbidity and mortality. The optimal cure for individual is still a controversy. Management is dictated by location of the perforation and concurrent injuries. Therefore, we review and evaluate the principles of clinical characteristic and treatment of perforations. Materials and Methods: A case-series study was conducted to describe etiology, clinical characteristic and to evaluate the outcomes of treatment for esophageal perforation at the Binh Dan hospital in a 5 years period, from 06.2014 to 06.2019 . Results: There were 36 patients, 24 male and 12 female, average age 46.6 years old Site of perforation includes 17 cases at cervix (47\%), 15 cases at thorax (42\%) and 4 cases at abdomen $(11 \%)$. Main mechanisms of esophageal injury are foreign bodies $(41.7 \%)$ and complication of gastric endoscopy (33.4\%). CT scan examination finds $93.9 \%$ cases. Non-operation treatment were successful in $6 / 8$ cases. The majority of cases are amenable to primary repair. Overall mortality in patients is estimated at $8.3 \%$. Conclusion: CT scan with oral contrast provides high sensitivity and reveals more finding information. Non-operation should be considered when the clinical situation allows for a less invasive approach. Primary repair is the treatment of choice for esophageal perforation with highly successful rate.

Key word: esophageal perforation, primary repair

\section{I. ĐĂT VẤN ĐỀ}

Thủng thực quản (TQ) là một cấp cứu ngoại khoa hiếm gặp, có tỉ lê biến chứng và tử vong cao. Điều trị bảo tồn thích hợp cho những trường hợp lỗ thủng thực quản nhỏ, phát hiện sớm, nhiễm trùng chưa lan rộng, tuy nhiên cần phải theo dõi sát bệnh nhân. Phẫu thuật khâu lỗ thủng thì đâu được xem là lựa chọn điều trị thích hợp nếu thủng thực quản được phát hiện trước 24 giờ. Hiện nay, thủng thực quản cũng có thể điều trị ít xâm lấn nhờ vào sự tiến bộ của kỹ thuật nội soi. Yếu tố chính giúp tiên lượng trong thủng thực quản là thời gian phát hiện.

Nguyển nhân hàng đâu gây thủng thực quản tại Việt Nam là do di vật. Dù đã có sự tiến bộ của các phương tiện hồi sức, tỉ lệ tử vong vẫn khoảng 20-30\%. Tại BV Bình Dân, tùy theo đặc điểm tổn thương và̀ tình trạng bệnh nhân, nhiều phương pháp điêu trị được áp dụng. Chúng tôi thực hiện đề tài nhằm mục đích mô tả nguyên nhân, cách xử trí đánh giá hiệu quả những phương pháp điều trị thủng thực quản trong 5 năm từ 06.2014 đến 06.2019.

\section{II. ĐỐI TƯỢNG VÀ PHƯƠNG PHÁP NGHIÊN CỨU}

Đối tượng nghiên cứu: những $B N$ nhập viện được chẩn đoán và điều trị thủng $\mathrm{TQ}$ tại bệnh viển Bình Dân trong khoảng thời gian 5 nắm từ 06.2014 đến 06.2019. Trong nghiên cứu này, chúng tôi loại bỏ các trường hợp bệnh nhân có $u$ thực quản phát hiện lúc chẩn đoán hoặc trước đó.

Thiết kế nghiên cứu: báo cáo hàng loạt ca.

\section{KẾT QUẢ NGHIÊN CỨU}

Trong thời gian 5 năm, có 36 trường hợp thủng TQ không do ung thư được điêu trị tại bệnh viện Bình Dân, trong đó có 24 bệnh nhân nam và 12 bệnh nhân nữ. Tuổi trung bình mắc bênh là $46,6 \pm 15,4$ tuổi $(18-84$ tuôi $), 75 \%$ bệnh nhân ở độ tuổi lao động (20-60 tuổi). Nguyên nhân gây thủng TQ gồm: dị vật đường tiêu hóa $(42 \%)$, tai biến nội soi $(33 \%)$, tai biến phẫu thuật $(8 \%)$, hội chứng Boerhaave $(16 \%)$. Dị vật tiểu hóa gây thủng $\mathrm{TQ}$ thường găp là xương $(67 \%)$, móc răng giả $(20 \%)$ và vỉ thuốc $(13 \%)$. Về vị trí tổn thương, có 17 ca tổn thương TQ cổ $(47 \%), 15$ ca tổn thương TQ ngực $(42 \%)$ và $4 \mathrm{ca}$ tổn thương TQ bụng $(11 \%)$.

Có $2 / 3$ bệnh nhân được chẩn đoán sớm (trước 24 tiếng). Hơn 90\% BN có triệu chứng đau ngực hoặc đau cổ. Khó thở chiếm tỉ lệ là $40 \%$. Có $42 \%$ BN có triệu chứng sốt và $64 \%$ BN có số lượng bạch câu trong máu cao hơn 10 K/uL. Số lượng bạch cầu trung bình là 13,4 $\pm 6,1$ $\mathrm{K} / \mathrm{uL}(4-29 \mathrm{~K} / \mathrm{uL})$. Hơn $50 \%$ BN có triệu chứng tổn thương khoang màng phổi lúc nhập viện. Tỉ lệ này ở nhóm $\mathrm{BN}$ phát hiện trê̂ là $83,3 \%$ so với nhóm phát hiện sớm là $37,5 \%$. Sự khác biệt này có ý nghĩa thống kê $(p<0,05)$. Sau nhập viên $24 \mathrm{~h}$, sẽ có thêm khoảng $40 \%$ BN xuất hiện tổn thương khoang màng phổi. Trong đó có $94,4 \%$ tràn dịch màng phổi, $25 \%$ tràn khí màng phối và $4 \%$ tràn mủ màng phổi.

Toàn bộ bệnh nhân có chụp X-quang ngực thẳng lúc nhập viện nhưng chỉ $67 \%$ phát hiện được hình ảnh bất thường. Dâu hiệu gián tiếp tổn thương màng phổi là triệu chứng được ghi nhận nhiều nhất, chiếm 50\%. Hình ảnh khí tư do quanh lỗ thủng chỉ ghi nhân được ở khoảng $40 \%$ trường hợp. Có 22 ca được chụp X-quang TQ cản quang và có $14(66,7 \%)$ trường hợp thấy thoát thuốc cản quang ra ngoài. Có $33 \mathrm{BN}$ được chụp MSCT cổ - ngực - bụng cao sau uống cản 
quang để đánh giá tổn thương, 31 trường hợp phát hiện tổn thương ngay lần đầu, chiểm 93,9\%. Có 26 trường hợp được nội soi TQ, phát hiện bất thường $19 \mathrm{ca}(73 \%)$.

Có 8 trường hợp được điều trị bảo tồn, tỉ lệ thành công là $75 \%$. 2 ca điều trị bảo tồn thất bại được theo dõi trong vòng 24 giờ và can thiệp phẩu thuật ngay khi phát hiện tình trạng nhiếm trùng lan rộng, thực hiện khâu thì đầu và đều thành công. Trong 30 ca phẫu thuật (bao gồm 2 ca điều trị bảo tồn thất bại) có 4 trường hợp phẫu thuât nội soi và 26 trường hợp mổ mở. $80 \%$ trường hợp được khâu thì đâu. Tỉ lệ thành công là $87,5 \%$. Có $3(12,5 \%)$ trường hợp thất bai gồm 2 ca thủng TQ ngực và 1 ca thủng $T Q$ cổ, phải mổ chuyển lưu cô lập TQ sau đó. Một số phương pháp khác bao gồm: phẩu thuâtt dẫn lưu đơn thuần $(6,7 \%)$, chuyển lưu TQ $(10 \%)$ và cắt TQ (3,3\%).

Thời gian nằm viên trung bình là $19,5 \pm 9,5$ ngày (4-40 ngày). Có khác biệt có ý nghĩa thống kê về thời gian trung bình nằm viện giữa 2 nhóm được chẩn đoán sớm và muộn $(p<0,05)$. Có $14 \%$ BN diễn tiến đến suy đa cơ quan và $60 \%$ trong số này sẽ tử vong. Tỉ lệ tử vong là $8,3 \%$. Yếu tố liên quan đến tử vong có ý nghĩa thống kê là thời gian chẩn đoán trễ hơn 24 giờ, tuổi lớn hơn 60 và bạch cầu lớn hơn 20K/uL lúc nhập viện.

\section{BÀN LUÂ̂N}

Thủng TQ là một bệnh cảnh hiếm gặp, nghiên cứu của chúng tổi ghi nhận được 36 trường hợp thủng TQ trong 5 năm. Về tuổi và giới tính, số liệu của chúng tôi khác so với một số tác giả trên thế giới nhưng tương đồng với các số liệu của các nghiên cứu ở Việt Nam ${ }^{(1,2,3)}$. Theo các nghiên cứu trong nước, thủng TQ thường găp ở lứa tuổi lao động (20-60 tuổi). Có thể lý giải do khác với thế giới là Việt Nam có dân số trẻ và nguyên nhân gây thủng $T Q$ chủ yếu là do dị vật tiêu hóa khi ăn uống. Nguyên nhân hàng đầu gây thủng $\mathrm{TQ}$ theo các nghiên cứu trên thế giới là do tai biến can thiệp y khoa chiếm trên $50 \%$ nguyên nhân gây thủng $\mathrm{TQ}^{(5,6,7)}$. Tại Việt Nam, dị vật là nguyên nhân hàng đầu gây thủng $T Q$, nghiên cứu của chúng tôi là $42 \%$. Dị vật xương dạng nhọn thường gây thủng TQ cổ và dị vật xương dạng mảnh thường kẹt và gây thủng TQQ ngực.

Triệu chứng của thủng TQ khác nhau tùy thuộc vào 3 yếu tố: vị trí thủng, cơ chế thủng và mức độ lan rộng của tổn thương. Trong bệnh cảnh thủng $\mathrm{TQ}$, triệu chứng thường gặp nhất là đau ngực, chiếm $70-80 \%$ trường hợp ${ }^{(7)}$. Triệu chứng đáp ứng viêm toàn thân có thể gặp như thở nhanh, mạch nhanh và sốt được xem như là triệu chứng muộn của thủng $T Q{ }^{(5,8,9)}$.

Trong thủng TQ, $77 \%-90 \%$ phim X-quang ngực thẳng có hình ảnh bất thường bao gồm tràn khí dưới da, tràn khí trung thất, tràn dịch, tràn khí màng phổi(10). Brinster đưa ra lưu ý là tràn khí dưới da cần tối thiểu một giờ mới xuất hiện và tràn dịch màng phổi, bung rộng trung thất chỉ xuất hiện sau thủng TQ 4-6 giờ (11). Xquang $\mathrm{TQ}$ cản quang từng được xem là tiêu chuẩn chẩn đoán thủng $\mathrm{TQ}^{(12)}$. Tuy nhiên, theo các nghiên cứu gần đây, tỉ lệ âm tính giả khi dùng $X$-quang $T Q$ cản quang để chẩn đoán thủng TQ lên đến $25-40 \%{ }^{(13)}$. Theo Marvroudis ${ }^{(14)}$, thuốc cản quang barium có giá trị chẩn đoán cao hơn so với cản quang tan trong nước do tính bám dính, tính trải bề mặt tốt hơn. Tuy vậy, trong tất cả các trường hợp, chúng tôi chỉ sử dụng thuốc cản quang tan trong nước nhằm tránh viêm hoại tử mô xung quanh khi thoát thuốc. Hình ảnh CT-scan cung cấp nhiều thông tin về thủng TQ: vị trí thủng, mức độ lan rộng, tổn thương đi kèm. Theo Young(13), hình ảnh hơi tự do chiếm $92 \%$ các trường hợp. Nghiên cứu chúng tôi cũng cho thấy $97 \%$ trường hợp có hình ảnh tràn khí ra xung quanh vị trí thủng. Ngoài việc đánh giá, $\mathrm{CT}$ còn giúp trong việc hướng dẫn điều trị, đặc biêt có ích trong những trường hợp có thể can thiệp thủ thuật ít xâm lấn như dẫn lưu, kiểm soát nhiễm trùng. Nội soi cung cấp hình ảnh trực tiếp trong lòng TQ. Nội soi TQ ống mềm là một phương án chẩn đoán thủng TQ. Độ nhạy và độ đặc hiệu của nội soi là $100 \%$ và $83 \%{ }^{(5)}$. Theo nghiên cứu của chúng tôi, tỉ lệ thây tổn thương là $75 \%$. Ngoài việc phát hiện lố thủng trong lòng $T Q$, dấu hiệu gợi ý khác gồm có viêm sướt lòng $T Q$, mủ hay giả mạc ở lòng $T Q$. Đa số các tác giả đều cho rằng nội soi không phải là phương tiện thường qui để chẩn đoán vì những lí do sau: có thể bỏ sót những tổn thương dạng nếp gấp; áp lực khí có khả năng đẩy làm lan rộng nhiếm trùng hay xé toạc tổn thương.

Những BN thỏa những điều kiện sau được chúng tôi điều trị bảo tồn: bệnh nhân ổn định, phát hiện sớm, tổn thương nhỏ, tình trạng dây nhiễm ra xung quanh không có hoặc rất ít, không có dấu hiệu nhiễm trùng, không có bệnh lý TQ trước đó. Nội dung điều trị gồm: ngưng ăn đường miệng, dinh dưỡng tĩnh mạch, đặt thông mũi dạ dày, kháng sinh phổ rộng và yếm khí, kháng tiết (ức chế bơm proton). BN sẽ được theo dõi sát và đánh giá lai sau mỗi 4-6 giờ. Nếu tình trạng nhiễm trùng không khống chế được 
hoặc có nguy cơ tiến triển nặng nề thêm thì tiến hành phẫu thuật ngay. Diễn tiến tự nhiên của thủng TQ có thể gây gây tràn dịch màng phổi do kích thích, nếu cần có thể đặt dẫn lưu màng phổi bổ sung. Theo các nghiên cứu của Lê Quang Nghĩa, Chirica, Hasimoto, khả năng điều trị bảo tồn thành công là 20 đến $35 \%$, tỉ lệ tử vong khoảng $10 \%(5,8,1)$. Nghiên cứu của chúng tôi có 8 BN được điều trị bảo tồn, tỉ lệ thành công là $75 \%$. Không có $B N$ nào tử vong do điều trị bảo tồn. Phẫu thuật nên được tiến hành càng sớm càng tốt ở tất cả BN không có đủ tiêu chí điều tri bảo tồn. Trì hoãn phẫu thuật sau võ 24 giờ sẽ làm tăng tỉ lệ tử vong của BN từ $10 \%$ lên $30 \%(5)$. Phẫu thuât nội soi có thể áp dụng ở các cơ sở y tế có phẫu thuật viên nhiều kinh nghiệm, trang thiết bị và phương tiện hồi sức tốt. Nguyên tắc phẫu thuật bao gồm: bộc lộ rộng rãi, loại bỏ mô hoại tử, đóng kín tổn thương, dẫn lưu đúng mức.

Tổn thương thủng TQ cổ nên được khâu thì đầu nếu có thể. Dẫn lưu đơn thuần cũng được xem là một phương pháp điều trị đối với thực quản cổ, đặc biệt trong những trường hợp nhiếm trùng do đến muộn hoặc tổn thương thực quản phức tạp không thể khâu lại thì đầu. Trong nghiên cứu của chúng tôi, tỉ lệ khâu thì đầu thành công là $89 \%, 1$ trường hợp $(11 \%)$ thất bại phải mở $\mathrm{TQ}$ cổ ra da do rò lớn chỗ khâu. Có 1 trường hợp chuyển lưu TQ ngay từ đầu do tổn thương hoại tử rộng và 2 trường hợp dẫn lưu đơn thuần. Các trường hợp này sau khi tình trạng nhiễm trùng ổn định được cho xuất viện và tạo hình $\mathrm{TQ}$ ở những lần nhập viện sau. Không có trường hợp thủng TQ cổ nào tử vong. Đối với thủng TQ ngực, điều trị khâu thì đầu gồm: ngăn tổn thương lan rông trung thất và màng phổi; cắt lọc lỗ thủng đến mô lành, khâu thì đầu "không căng", dẩn lưu ra ngoài đủ rộng ${ }^{(4,5)}$. Khâu tổn thương thực quản ngực cần bộc lộ rộng để thấy được 2 đầu niêm mạc tổn thương và khâu 2 lớp riêng biệt. BN cần đặt dẫn lưu ở khoang màng phổi và cạnh lỗ thủng bằng ống dẫn lưu lớn. Dân lưu này nên được đặt cho đển khi tổn thương TQ lành và lưu thổng TQ tốt. Vấn đề này được kiểm tra sau mổ 7 ngày bằng việc cho chiếu và chụp TQ lúc nuốt cản quang. Đường mổ có thể rất khác nhau tùy vào vị trí tổn thương và tùy vào kinh nghiệm của phẫu thuật viên. Tỉ lệ thành công của chúng tôi là $82 \%$. Theo Chirica( ${ }^{(5)}$, những trường hợp khâu thì đầu cần phải mở da dày ra da kết hợp với đặt ống thông mũi da dày nhằm mục đích giải áp, chống trào ngược dịch dạ dày và có thể cho $B N$ ăn sớm. Trong trường hợp không thể khâu TQ thì đầu như huyết động không ổn định, thủng TQ phát hiện trề, tổn thương $T Q$ rộng thì cần thực hiện những phẫu thuật khác như đặt ống dẫn lưu chữ $T$ lớn vào lòng $T Q$ để tạo đường dò chủ động, chuyển lưu TQ và cắt TQ. Hiện nay, cắt TQ là lựa chọn tối ưu ở $B N$ thủng TQ do bệnh lý $(4,5)$. Thủng TQ bụng nên mở bụng đường giữa trên rốn hơn là mở ngực để tiếp cận tổn thương. Thực quản bụng có thể khâu một lớp hoặc 2 lớp, dùng đáy vị để khâu tăng cường nếu cần, đặt thông dạ dày và mở dạ dày hoặc hỗng tràng nuôi ăn ${ }^{(5)}$. Với sự tiến bộ về kỹ thuật và dụng cụ, ngày nay, PTNS gần như có thể tiếp cận trong hầu hết các trường hợp.

Năm 2004, Brinster ${ }^{(11)}$ thực hiện một nghiên cứu gộp trên $726 \mathrm{BN}$ cho thấy tỉ lệ tử vong chung là $18 \%$, do thủng $\mathrm{TQ}$ cổ là $6 \%$, thủng TQ ngực là $27 \%$. Chậm trễ trong chẩn đoán và điêu trị là yếu tố hàng đầu liên quan tiên lượng. Tỉ lệ tử vong tăng lên gấp đôi nếu điều trị sau 24 giờ. Đến nay, tî lệ tử vong vẫn không có sự thay đổi đáng kể(17). Tî lệ tử vong theo nghiên cứu của chúng tôi là $8,3 \%$. Cả 3 trường hợp đều thủng TQ ngực, đến trễ; nguyên nhân gây thủng TQ ở những trường hợp tử vong là: một do dị vật thực quản (xương cá), một do tự phát và một do tai biến phẫu thuật (cắt u trung thất).

\section{KẾT LUÂN}

Thủng thực quản là một bệnh cảnh hiếm gặp, có đặc điểm lâm sàng đa dạng và diễn tiến phức tạp. Tại Việt Nam, nguyên nhân chiếm phần lớn vần là dị vật xương động vật. CT-scan có độ nhạy cao, cho nhiều thông tin giúp chẩn đoán và điều trị. Những BN đến sớm có thể không có triệu chứng trên chẩn đoán hình ảnh, cần chú ý để tránh bỏ sót bệnh. Điều trị bảo tồn có thể áp dụng trong một số trường hợp chọn lọc và cần phải theo dõi sát. Khâu thì đầu là một lựa chọn có tỉ lệ thành công cao. Phẫu thuật vẫn là phương pháp điều trị tốt nhất. Hiện tại việc điều trị bằng các kỹ thuật ít xâm lấn có thể áp dụng trong một số trường hợp.

Nghiển cứu này được tài trợ bởi Đại học Quốc gia Thành phố Hồ Chí Minh (ĐHQG-HCM) trong khuôn khổ Đề tài mã số C2020-44-08

\section{TÀI LIÊU THAM KHẢO}

1. Lê Quang Nghĩa (2012) "Thủng, bục miêng nối và do thực quản". Tạp chí Y học Thành phố Hố Chí Minh 16, tr. 2-4.

2. Lê Quang Nhân (2015) "Nôi soi khâu kín lỗ thủng thực quản bằng over-the-scope clip: một ca lâm sàng". Tạp chí Y học Thành phố Hồ Chí Minh, 19 , tr. 39-42.

3. Nguyễn Công Minh (2013) "Hội chứng 
Boerhaave hay Hội chứng võ̃ thực quản do nôn ói mạnh tại bệnh viển Chợ Rẫy và Bệnh viện cấp cứu Trưng Vương trong 14 năm (1999-2012)". Tạp chí Y học Thành phố Hồ Chí Minh, 17, tr. 44-52.

4. Huu Vinh V., Viet Dang Quang N., Van Khoi N. (2019) "Surgical management of esophageal perforation: role of primary closure". Asian Cardiovasc Thorac Ann, 27 (3), tr. 192-198.

5. Chirica Mircea, Kelly Michael D., Siboni Stefano, Aiolfi Alberto, Riva Carlo Galdino, Asti Emanuelevà cộng sự (2019) "Esophageal emergencies: WSES guidelines". World Journal of Emergency Surgery, 14 (1), tr. 26.

6. Dickinson Karen Joanna, Blackmon Shanda $H$. (2015) "Endoscopic Techniques for the Management of Esophageal Perforation". Operative Techniques in Thoracic and Cardiovascular Surgery, 20 (3), tr. 251-278.

7. Soreide J. A., Viste A. (2011) "Esophageal perforation: diagnostic work-up and clinical decision-making in the first 24 hours". Scand J Trauma Resusc Emerg Med, 19, tr. 66

8. Hasimoto C. N., Cataneo C., Eldib R., Thomazi R., Pereira R. S., Minossi J. G.và cộng sự (2013) "Efficacy of surgical versus conservative treatment in esophageal perforation: a systematic review of case series studies". Acta Cir Bras, 28 (4), tr. 266-71.

9. Misiak P., Jablonski S., Piskorz L., Dorozala L., Terlecki A., Wcislo S. (2017) "Oesophageal perforation - therapeutic and diagnostics challenge. Retrospective, single-center case report analysis (2009-2015)". Pol Przegl Chir, 89 (4), tr. 1-4.

10. White C. S., Templeton P. A., Attar S. (1993) "Esophageal perforation: CT findings". AJR Am J Roentgenol, 160 (4), tr. 767-70.

11. Brinster C. J., Singhal S., Lee L., Marshall M. B., Kaiser L. R., Kucharczuk J. C. (2004) "Evolving options in the management of esophageal perforation". Ann Thorac Surg, 77 (4), tr. 1475-83.

12. Attar S., Hankins J. R., Suter C. M., Coughlin T. R., Sequeira A., McLaughlin J. S. (1990) "Esophageal perforation: a therapeutic challenge". Ann Thorac Surg, 50 (1), tr. 45-9; discussion 50-1.

13. Young C. A., Menias C. O., Bhalla S., Prasad S. R. (2008) "CT features of esophageal emergencies". Radiographics, 28 (6), tr. 1541-53.

14. Mavroudis Constantine $D$., Kucharczuk John C. (2013) "Acute Management of Esophageal Perforation". Current Surgery Reports, 2 (1), tr. 34.

15. Sdralis E. I. K., Petousis S., Rashid F., Lorenzi B., Charalabopoulos A. (2017) "Epidemiology, diagnosis, and management of esophageal perforations: systematic review". Dis Esophagus, 30 (8), tr. 1-6.

16. Wright C. D., Mathisen D. J., Wain J. C., Moncure A. C., Hilgenberg A. D., Grillo H. C. (1995) "Reinforced primary repair of thoracic esophageal perforation". Ann Thorac Surg, 60 (2), tr. 245-8; discussion 248-9.

17. Blasberg Justin D., Wright Cameron D. (2015) "Management of Esophageal Perforation". Adult Chest Surgery. 2nd ed. McGraw-Hill,

\section{THỰC TRẠNG KIẾN THỨC THỰC HÀNH VỀ TUÂN THỦ ĐIỀU TRI CỦA NGƯờI BỆNH TĂNG HUYẾT ÁP VÀ MộT SỐ YẾU TỐ LIÊN QUAN TẠI BỆNH VIÊ̂N BACCH MAI}

\section{TÓM TẮT}

Nghiên cứu mô tả cắt ngang kết hợp phân tích thực hiên trên 384 bênh nhân tai Khoa Khám bênh, Bệnh viện Bạch Mai từ tháng 12/2020 đến tháng 5/2021 trên bệnh nhân tăng huyết áp đến khám bệnh tai bệnh viên Bach Mai. Mục tiêu phân tích tuân thủ điều trị, chằm sóc người bệnh tăng huyết áp và một số yếu tố liên quan. Có đạt kiến thức chung về tăng huyết áp là $68 \%$ và chưa đạt về kiến thức chiếm $32 \%$. Thực hành chung về điều trị tăng huyết áp mức đạt là $40,9 \%$ và chưa đạt là $59,1 \%$; Về tuân thủ thực hành điêu trị tăng huyết áp tốt chiếm $63,5 \%$ và tuân thủ chưa tốt chiếm 36,5\%; Có sự khác biệt rõ rệt và

\section{${ }^{1}$ Bệnh viện Bach Mai}

${ }^{2}$ Trường $\oplus H$ Thăng Long

Chịu trách nhiệm chính: Nguyễn Thị Hường

Email: huongnguyebvbm@gmail.com

Ngày nhận bài: 26.10.2021

Ngày phản biên khoa hoc: 23.12.2021

Ngày duyệt bài: 30.12.2021

\section{Nguyễn Thị Hường1, Lê Thị Bình ${ }^{2}$}

có ý nghĩa thống kê giữa tuổi > 60 tuổi và $<60$ tuổi với tuân thủ điều trị $(p<0,05)$, giữa $B M I<18,5$ và $18,5-23(p<0,05)$, giữa BMI < 18,5 và > 23 ( $p<$ $0,05)$, giữa thời gian bị THA mắc bệnh trên 10 năm và dưới 10 năm với tuân thủ điêu trị $(p<0,000)$. Giữa đã từng có biến chứng và không với tuân thủ điêu trị ( $p$ $<0,000)$. Giữa có tăng Lipid máu với tuân thủ điêu tri $(p<0,000)$. Giữa kiến thức chưa đạt và có kiến thức đat với tuân thủ điều trị $(p<0,000)$; giữa nhóm BMI với kiến thức; giữa thời gian bị bệnh $<5$ năm và $>5$ năm với kiến thức $(p<0,05)$; giữa đã từng bi biến chứng với thực hành $(p<0,05)$. Giữa Kiến thức về tăng huyết áp đạt và chưa đạt với thực hành đạt và chưa đạt $(p<0,000)$

Keywords: Treatment adherence, knowledge, practice, care, counseling for patients

\section{SUMMARY \\ CURRENT STATUS OF KNOWLEDGE AND \\ PRACTICE ON TREATMENT ADHERENCE OF HYPERTENSIVE PATIENTS AND SOME RELATED FACTORS AT BACH MAI HOSPITAL}

